\title{
PELATIHAN DASAR-DASAR CAD/CAM/CAE DAN SOFTWARE AUTOCAD UNTUK GURU-GURU SMK BIDANG KEAHLIAN TEKNIK MESIN DI WILAYAH KABUPATEN BEKASI
}

\author{
Ragil Sukarno $^{1)}$, I Wayan Sugita ${ }^{2)}$, Eko Arif Syaefudin ${ }^{3)}$ \\ Jurusan Teknik Mesin, Fakultas Teknik, Universitas Negeri Jakarta \\ ragil.sukarno01@yahoo.com
}

\begin{abstract}
ABSTRAK
Di dunia industri, proses desain sebuah produk tidak lagi menggunakan cara-cara yang konvensional, akan tetapi menggunakan sebuah sarana komputer melalui sebuah software desain dan optimasi yang biasa disebut dengan istilah $\mathrm{CAD} / \mathrm{CAM} / \mathrm{CAE}$. Namun, seiring dengan tantangan persaingan global yang sudah didepan mata, masih banyak guru-guru SMK terutama di wilayah Kecamatan Tarumajaya dan sekitarnya di Kabupaten Bekasi yang belum mumpuni dalam penguasaan teknologi informasi atau teknologi komputer di bidang desain dan analisa. Tujuan dari kegiatan pelatihan ini adalah untuk memberikan pengetahuan baru kepada guru teknik mesin di wilayah Kabupaten Bekasi, khususnya SMK di Tarumajaya dan sekitarnya melalui pengenalan teknologi CAD/CAM/CAE dan pelatihan AutoCAD, sehingga bisa menjadi alternatif proses desain dan perancangan produk dari metode konvensional ke metode komputerisasi. Metode yang digunakan pada pelatihan ini adalah melalui teori, praktek dan diskusi serta memberikan tugas kepada peserta agar langsung mempraktekan materi yang telah disampaikan. Materi yang diberikan dalam pelatihan adalah pengenalan dasar-dasar CAD/CAM/CAE dan menggambar objek 2 dimensi dan 3 dimensi dengan menggunakan software AutoCAD. Program pelatihan ini dapat diselenggarakan dengan baik dan berjalan dengan lancar sesuai dengan rencana kegiatan yang telah disusun serta mendapat sambutan yang sangat baik terbukti dengan keaktifan peserta mengikuti pelatihan dengan tidak meninggalkan tempat sebelum waktu pelatihan berakhir. Terjadinya peningkatan pengetahuan tentang konsep perancangan produk melalui pengenalan dasar-dasar CAD/CAM/CAE dan peningkatan kemampuan dan motivasi dalam mendalami desain dengan software CAD, khususnya AutoCAD. Kegiatan ini sangat bermanfaat bagi guru-guru SMK bidang keahlian teknik mesin di wilayah kabupaten Bekasi, Jawa Barat
\end{abstract}

\section{Kata kunci : desain produk, CAD/CAM/CAD, AutoCAD}

\section{PENDAHULUAN}

\section{A. Analisis Situasi}

Perkembangan teknologi informasi

dan komputer sekarang ini berlangsung dengan sangat cepat. Hampir semua bidang pekerjaan dan kegiatan di sekitar kita selalu dihubungkan dengan sistem yang terhubung dengan teknologi infor-masi dan pemanfaatan komputer. Sehingga penguasaan aplikasiaplikasi komputer mutlak diperlukan bagi siapa saja yang ingin menyelesaikan bidang pekerjaan atau kegiatan dengan lebih mudah dan lebih cepat.
Bidang keahlian Teknik Mesin saat ini telah mengalami perkembangan yang sangat pesat, terutama dalam bidang desain produk dan optimasi desain. Di dunia industri, proses desain sebuah produk tidak lagi menggunakan cara-cara yang konvensional, akan tetapi menggunakan sebuah sarana komputer melalui sebuah software desain dan optimasi yang biasa disebut dengan istilah CAD/CAM/ CAE. Perusahaan-perusahaan manufaktur multinasional seperti Astra, LG, Samsung, Panasonic telah mengaplikasikan teknologi 
$\mathrm{CAD} / \mathrm{CAM} / \mathrm{CAE}$ dalam seluruh proses desain di perusahaan mereka. Ini sangat diperlukan untuk mendapatkan desain yang cepat, sempurna dan mengurangi kecacatan desain. Penguasaan terhadap software ini akan sangat membantu para guru Teknik Mesin di SMK dalam menyampaikan sebuah materi didepan siswa secara lebih mudah dan interaktif.

Sejalan dengan itu, penguasaan aplikasi software CAD/CAM/CAE menjadi sangat penting bagi siswa-siswa SMK terutama untuk menyambut persaingan global seiring dengan pemberlakuan AFTA (ASEAN Free Trade Area) pada tahun 2015. Kesiapan Indonesia harus diterjemahkan dari sisi hard skill (teknologi) atau Soft skill (Sumber Daya Manusia). Oleh karena itu dalam mempersiapkan lulusan SMK yang mampu bersaing di persaingan global dibutuhkan guru-guru yang mumpuni terhadap perkembangan teknologi terbaru.

Namun, seiring dengan tantangan persaingan global yang sudah didepan mata, masih banyak guru-guru SMK terutama di wilayah Kecamatan Tarumajaya dan sekitarnya di Kabupaten Bekasi yang belum mumpuni dalam penguasaan teknologi informasi atau teknologi komputer di bidang desain dan analisa. Wilayah ini berbatasan langsung dengan DKI Jakarta, namun sangat jauh dari pusat pemerintahan Kabupaten Bekasi, sehingga dibutuhkan suatu suntikan ilmu pengetahuan baru untuk meningkatkan kualitas mereka. Dan berdasarkan masukan dari guru-guru di wilayah Tarumajaya, masih diperlukan adanya pelatihan-pelatihan bagi guru dalam upaya meningkatkan kualitas pendidikan di wilayah tersebut. Peran perguruan tinggi dari sisi peningkatan sumber daya manusia bagi guru-guru teknik mesin sangat diperlukan, Pada pelatihan ini akan diperkenalkan Aplikasi Software CAD/ CAM/ CAE dan khususnya AutoCAD untuk guruguru di Sekolah Menengah Kejuruan, dan secara khusus pelatihan ini akan dilaksanakan di Kecamatan Tarumajaya Bekasi.
Program pelatihan ini, diharapkan akan meningkatkan kemampuan guru-guru di Sekolah Menengah Kejuruan di Kecamatan Tarumajaya Bekasi terhadap penguasaan aplikasi komputer di bidang desain Teknik Mesin, sehingga diharapkan juga bisa menghasilkan sebuah metode penyampaian pelajaran teknik mesin yang mudah dimengerti dan akan menjadi bekal bagi siswa untuk bersaing di dunia kerja setelah lulus nanti.

\section{B. Tujuan Kegiatan}

Tujuan dari kegiatan ini adalah untuk memberikan pengetahuan baru kepada guru teknik mesin di Kabupaten Bekasi, khususnya Sekolah Menengah Kejuruan di Tarumajaya dan sekitarnya melalui pengenalan teknologi CAD/CAM/ CAE dan pelatihan Auto CAD. Sehingga bisa menjadi alternative proses desain dan perancangan produk dari metode konvensional ke metode komputerisasi.

\section{Metode Penerapan Iptek}

Metode yang digunakan pada program ini adalah teori, praktek dan diskusi. Teori diberikan dalam bentuk pengajaran didalam kelas. Sedangkan praktek akan dilakukan secara individu di dalam kelas dengan cara menyelesaikan beberapa latihan yang telah disiapkan oleh pengajar.

Langkah-langkah kegiatan "Pelatihan Dasar-Dasar CAD/CAM/ CAE dan Software AutoCAD Untuk Guru-Guru SMK di Wilayah Kabupaten Bekasi" adalah sebagai berikut :

1. Nara sumber mempresentasikan tentang Dasar-Dasar CAD/CAM/CAE

2. Nara sumber mempresentasikan atau menjelaskan awal tentang materi AutoCAD 2 Dimensi dan AutoCAD 3 Dimensi

3. Nara sumber membimbing peserta mengoperasikan Auto CAD dan mengerjakan soal-soal latihan desain 2 dimensi dan 3 dimensi yang disediakan.

4. Melalui tanya jawab dan bimbingan, guru menanyakan tentang kesulitan-kesulitan dalam pengoperasian software AutoCAD dan nara sumber meresponnya. 
5. Guru secara mandiri di beri tugas untuk menyelesaikan beberapa soal dengan menggunakan software Auto CAD.

6. Nara sumber dan tim membantu guru yang masih kesulitan dalam mengerjakan tugas.

7. Beberapa guru mempresen-tasikan hasil kerja nyata

\section{TINJAUAN PUSTAKA}

A. Dasar-Dasar CAD/CAM/CAE

$\mathrm{CAD} / \mathrm{CAM} / \mathrm{CAE}$ adalah kesatuan dari program kumputer dalam bidang teknik mesin yang secara khusus disiapkan untuk membantu dalam proses desain produk agar dihasilkan sebuah produk yang berkualitas bagus, bisa dilakukan dengan cepat dan untuk menghindari cacat produk sehingga akan dihasilkan penghematan biaya pada proses desain dan persiapan sebelum produksi massal. CAD atau Computer Aided Design adalah suatu perangkat lunak atau program computer yang digunakan untuk menggambar suatu produk atau bagian dari suatu produk berupa 2D maupun 3D. Banyak Software CAD yang telah digunakan, diantaranya adalah AutoCAD, Pro Engineering, CATIA, Inventor dan masih banyak yang lain. Tapi pada pelatihan ini, yang akan diperkenalkan adalah AutoCAD. CAM atau Computer Aided Manufacturing adalah sebuah sistem yang secara otomatis mampu menghasilkan produk atau benda kerja melalui penggunaan perangkat permesinan yang dikendalikan oleh komputer. Sedangkan CAE atau Computer Aided Engineering merupakan teknologi penghitungan karakteristik dari suatu produk atau bagian dari suatu produk dengan bantuan komputer. Dalam perencanaan atau perancangan suatu produk tidak cukup hanya dengan drawing atau gambar saja, tapi juga diperlukan untuk mengetahui karakteristik dari produk yang dirancang tersebut baik secara mekanika-statis, dinamis, maupun thermal, dan karakteristik lainnya yaitu dengan cara menganalisa produk rancangan tersebut. Sedangkan software CAE yang telah beredar diantaranya adalah MSC Nastran, CATIA, ANSYS, dan lain-lain.

Proses desain yang bisa dilakukan dengan menggunakan program komputer CAD/ CAM dan CAE adalah sebagai berikut :

\section{CAD : Computer Aided Design}

Teknologi ini digunakan untuk mendesain komponen atau produk.

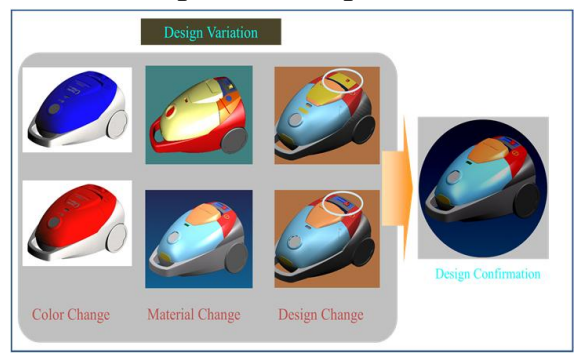

Tampilan Proses Desain - CAD

\section{CAM : Computer Aided Manufacturing}

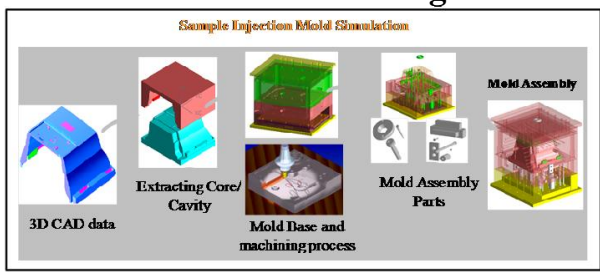

Tampilan Proses Manufacturing - CAM

\section{CAE : Computer Aided Engineering} Simulasi

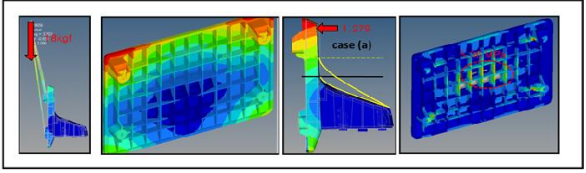

Tampilan Proses Analisis Desain - CAE

Untuk mendesain sebuah produk mulai dari awal sampai menjadi produk jadi biasanya melalui tahapan sebagai berikut :

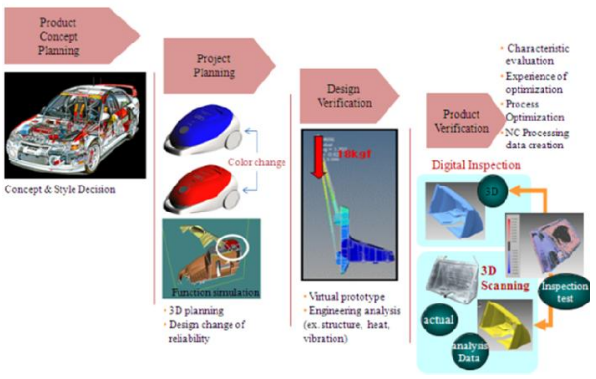

Proses Desain dan Pengembangan Produk 
Dari gambar dibawah ini anda bisa melihat perbedaan tahapan proses pengembangan produk yang secara konvensional dan dengan memanfaatkan $\mathrm{C} 4$ (CAD/CAM/ CAE/CAT) melibatkan simulasi engineering. CAT (Computer Aided Testing) adalah metode testing produk dengan menggunakan software simulasi

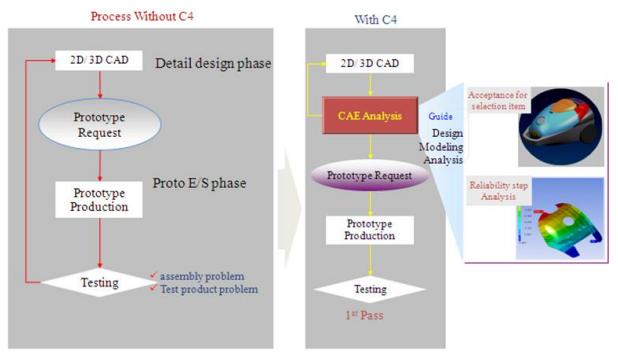

Perbedaan Proses Pengembangan Produk Dengan dan tanpa CAD/ CAM/CAE dan CAT (Computer Aided Testing)

Point penting yang harus diperhatikan dalam simulasi engineering adalah

1. Indentifikasi masalah

2. Indentifikasi beban

3. Indentifikasi batas

4. Properties dari material

5. Analisis komponen

6. Opsi perbaikan atau pengem-bangan ide untuk pengembangan

\section{B. Desain AutoCAD 2 Dimensi}

CAD (Computer Aided Design) merupakan alat bantu untuk merancang gambar berbasis komputer. Sistem CAD banyak digunakan dibidang mesin, arsitektur, sipil, elektronika, bahkan periklanan. AutoCAD merupakan software CAD yang paling sederhana untuk belajar menggambar dua dimensi dan tiga dimensi. Salah satu program keluaran Autodesk Inc. dijadikan sebagai basic training dalam pengusaan CAD sehingga cocok bagi pemula. Keunggulan dari software ini memiliki antara lain keakuratan, detail dan ketelitian, yang pasti lebih baik daripada membuat gambar teknik secara manual, dan pengguna dapat memahami dengan cepat karena dilengkapi fitur-fitur yg banyak dan menarik.

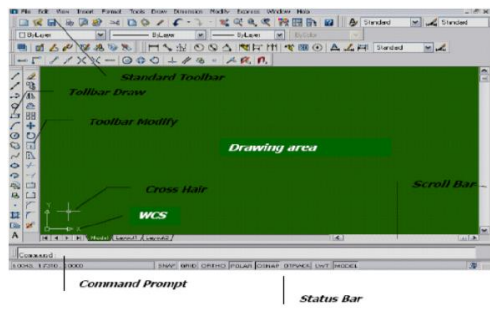

Bidang Gambar AutoCAD

Untuk membuat gambar konstruksi geometrik maupun komponen mesin diperlukan pengetahuan perintah-perintah meng-gambar yang ada di dalam software AutoCAD. Adapun perintah-perintah dasar yang paling banyak digunakan adalah sebagai berikut :

L (line) : untuk membuat garis

E (erase) : untuk menghapus objek

F (fillet) : untuk menghubungkan dua garis yang tidak sejajar

Ex (extend) : untuk memanjangkan garis dengan batas garis yang lainnya

Tr (trim) : untuk memotong garis

Cp (copy) : untuk memperbanyak objek

$\mathbf{M}$ (move) : untuk memindahkan objek

$\mathbf{O}$ (offset) : memperbanyak garis dengan jarak yang ditentukan

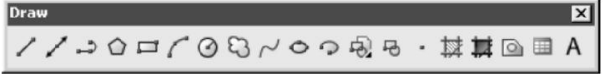

Toolbar Draw

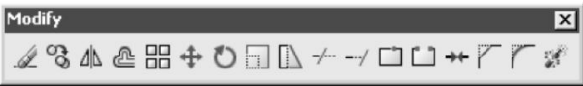

Toolbar Modify

Dalam pelatihan AutoCAD 2 dimensi, para peserta diharapkan bisa menguasai materi dasar menggambar dan modifikasi gambar 2 dimensi.

\section{Desain AutoCAD 3 Dimensi}


Membuat gambar 3D bagi pemula akan terasa sulit dan tidak tahu dari mana akan memulai. Tetapi bila kita sebagai pemula sudah mahir di 2D itu bukan masalah, sekarang tinggal pemahaman gambar 3D, gambar 3D adalah gambar 2D yang di extrude (dibuat ada ketinggian), ketinggiannya akan terlihat apabila "WCS" di rubah menjadi "UCS", selama posisi dalam keadaan "WCS" gambar 3Dnya tidak akan nampak, karena posisi "WCS" sama dengan anda melihat dari atas.

Hal pertama yang harus dikuasai dalam menggambar 3 dimensi adalah kita harus mengetahui sudut pandang (view), mengatur koordinat (UCS), dan bidang gambar.

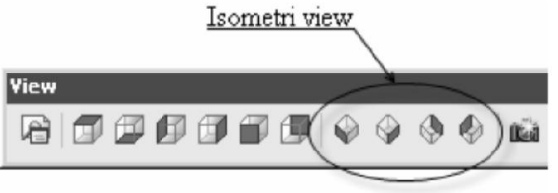

Tool View (Sudut Pandang)

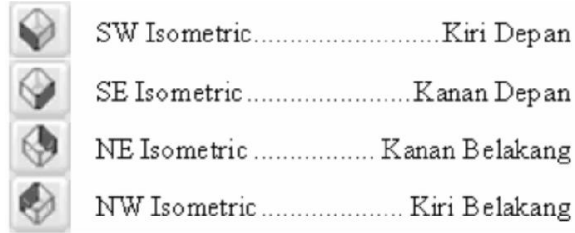

Tool View Isometric

Perintah dasar menggambar Draw sama dengan 2 dimensi yaitu dengan menggunakan tool draw. Dan untuk membuat objek 3 dimensi, kita akan menggunakan tool sebagai berikut

\begin{tabular}{|c|c|c|c|}
\hline Bentuk & COMMAND & Icos & Keterangan \\
\hline BOX & BOX & च & Membuat box solid \\
\hline BOLA & SPHERE & $\theta$ & Membuat bola solid \\
\hline SILNDER & CYLINDER & 10 & Membuat silinder solid \\
\hline KERUCUT & CONE & $\Delta$ & Membuat kerueut solid. \\
\hline WEDGE & WEDGE & $\Delta$ & Membuat wedge solid \\
\hline TORUS & TORUS & 0 & Membuat torus solid \\
\hline
\end{tabular}

Toolbar Objek 3 dimensi

Dalam menggambar objek 3 dimensi,terkadang kita tidak bisa menggambarkan sekali jadi, tapi biasanya dilakukan dengan beberapa tahap misalkan, melakukan penggabungan (Union), pemotongan, interseksi, fillet dan yang lainya. Dan tool yang digunakan adalah sama dengan yang kita gunakan dalam modify object 2 dimensi seperti pada gambar 8 .

Operasi ini hanya berlaku untuk object solid. Dengan operasi modify ini kita dapat mengkombinasikan object-object standar menjadi bentuk yang lebih kompleks. Perintah-perintah yang termasuk pada operasi bolean ini dapat dilihat pada gambar berikut

\begin{tabular}{|c|c|c|l|}
\hline COMMAND & INPUT & ICON & \multicolumn{1}{|c|}{ Keterangan } \\
\hline $\begin{array}{c}\text { UNION } \\
\text { (Boolean) }\end{array}$ & UNI & Q & Menyatukan objek \\
\hline $\begin{array}{c}\text { SUBTRACT } \\
\text { (Boolean) }\end{array}$ & SU & $\mathbf{Q}$ & Memotong objek dengan objek lain \\
\hline $\begin{array}{c}\text { INTERSECT } \\
\text { (Boolean) }\end{array}$ & IN & $\mathbf{Q}$ & Irisan objek \\
\hline $\begin{array}{c}\text { EXTRUDE } \\
\text { FACE }\end{array}$ & $\begin{array}{c}\text { SOLID } \\
\text { EDIT }\end{array}$ & $\mathbf{D I}$ & $\begin{array}{l}\text { Menambah ukuran salah satu } \\
\text { permukaan }\end{array}$ \\
\hline SLICE & SLICE & $\mathbf{2}$ & Memotong objek langsung \\
\hline
\end{tabular}

Toolbar Modify 3 dimensi

Dalam pelatihan AutoCAD D dimensi, para peserta diharapkan bisa menguasai materi dasar menggambar dan modifikasi gambar 2 dan 3 dimensi dari tugas yang telah disiapkan oleh tim narasumber atau pengajar.

\section{HASIL DAN PEMBAHASAN}

Kegiatan pelatihan ini dilak-sanakan dari pukul 08.00-17.00 WIB. Peserta kegiatan berjumlah 23 orang guru-guru SMK bidang teknik mesin di wilayah Kecamatan Tarumajaya dan sekitarnya Kabupaten Bekasi. Lokasi penyelenggaraan pelatihan adalah di SMK N 1 Tarumajaya, Kabupaten Bekasi.

Kegiatan pelatihan yang dilaksanakan dengan acara tatap muka dan praktek dalam pengenalan dasar-dasar CAD/CAM/CAE dan penggunaan software AutoCAD berjalan dengan baik dan lancar. Pertemuan tatap muka dengan metode ceramah dan demonstrasi dilanjutkan latihan atau praktek untuk membuat gambar 2 dimensi dan 3 dimensi dengan software AutoCAD.

Pelaksanan kegiatan P2M ini dilakukan oleh beberapa tim narasumber atau pengajar 
dengan pokok bahasan yang disampaikan mengenai:

\section{Menjelaskan dasar-dasar CAD/ CAM/CAE}

Kegiatan yang diawali dengan ceramah dan demonstrasi ini kemudian dilanjutkan latihan dan tugas. Dari kegiatan latihan tampak bahwa sebagian besar guru memang belum memahami taknologi CAD/CAM/CAE. Namun selama pelaksanaan pelatihan dasar-dasar CAD/CAM/CAE, peserta dapat memahami dengan cepat dan sangat antusias menerima materi dari narasumber. dan diharapkan menjadi bekal bagi guru peserta pelatihan dalam memberikan bekal dan motivasi belajar kepada siswa. Pelatihan untuk pengenalan $\mathrm{CAD} / \mathrm{CAM} / \mathrm{CAE}$ ini selama 1,5 jam.

\section{Penjelasan Materi dan Langkah- langkah pengoperasian AutoCAD 2 Dimensi}

Pelatihan AutoCAD 2 dimensi ini dilakukan selama 2,5 jam. Nara sumber memperkenalkan teknik menggambar dan contoh-contoh dalam menggambar CAD dalam 2 dimensi.

\section{Penjelasan Materi dan Langkah- langkah pengoperasian AutoCAD 3 Dimensi}

Sama dengan pelatihan sebelumnya, pelatihan diawali dengan paparan materi dan contoh-contoh dari narasumber dan dilanjutkan pemberian latihan dan tugas kepada peserta. Dalam materi ketiga ini, kegiatan pelatihan berjalan lebih lama karena memang materi menggambar AutoCAD 3 dimensi ini membutuhkan dasar yang kuat dari 2 dimensi. Peserta membutuhkan pendampingan dan bimbingan yang sangat ekstra dari nara sumber dan tim karena mengalami kesulitan dalam mengerjakan contoh-contoh latihan dan tugas. Materi Auto CAD 3 dimensi ini dilaksanakan selama 4 jam.

\section{Evaluasi hasil pengoperasian AutoCAD 2D dan 3D}

Berbagai pertanyaan diajukan secara antusias oleh para peserta dalam sesi tanya jawab dan dalam mengerjakan tugas. Secara garis besar inti dari pertanyaan para peserta adalah:

1. Bagaimana Aplikasi CAD/ CAM/CAE di industri dan apa kegunaanya bagi guru dan murid menguasai materi ini

2. Langkah-langkah pengoperasian software Auto CAD 2 dimensi

3. Langkah-langkah pengoperasian software AutoCAD 2 dimensi

4. Pengaturan tampilan atau view, penggantian koordinat (UCS), modify gambar, dan bagaimana cara mudah dalam menyelesai-kan tugas yang telah diberikan

Dari hasil pemantauan selama
pelaksanaan pelatihan ini perserta berpartisipasi sangat aktif. Ini ditunjukkan dengan aktifitas para peserta untuk bertanya dan meminta bimbingan kepada para narasumber bila menemui kesulitan. Para peserta juga menunjukkan kesungguhan, ini ditunjukkan oleh semua peserta yang mengerjakan semua latihan dan tugas yang diberikan oleh narasumber. Dalam pelatihan ini juga nampak semangat kerjasama dan hubungan sosial yang baik diantara paserta dan narasumber. Mereka saling membantu dan selalu bersemangat untuk menyelesaikan tugas yang telah diberikan oleh narasumber.

Kedisiplinan yang cukup baik dikalangan guru nampak dari ketepatan waktu pelaksanaan pelatihan, demikian pula keaktifan bertanyapun. Nampak dari banyaknya pertanyaan yang diajukan kepada fasilitator, menunjukkan bahwa pelatihan ini merupakan sesuatu yang baru bagi guru SMK di wilayah Kabupaten Bekasi, khususnya Tarumajaya dan sekitarnya. .

Hasil kegiatan pelatihan dalam pengabdian kepada masyarakat secara garis besar mencakup beberapa komponen sebagai berikut:

1. Keberhasilan target jumlah peserta pelatihan 
2. Ketercapaian tujuan pelatihan

3. Ketercapaian target materi yang telah direncanakan

4. Kemampuan peserta dalam penguasaan materi

Target peserta pelatihan seperti direncanakan sebelumnya adalah paling tidak 20 guru SMK di wilayah Kecamatan Tarumajaya, sesuai dengan kapasitas kelas dan efektifitas pelaksanaan pelatihan. Dalam pelaksanaannya, kegiatan ini diikuti oleh 23 orang peserta. Dengan demikian dapat dikatakan bahwa target peserta tercapai $115 \%$. Angka tersebut menunjukkan bahwa kegiatan P2M dilihat dari jumlah peserta yang mengikuti dapat dikatakan berhasil atau sukses.

Ketercapaian tujuan pelatihan sudah baik . Ini dilihat dari hasil latihan para peserta yaitu kualitas penggunaan software AutoCAD yang telah dihasilkan dan penguasaan materi tentang $\mathrm{CAD} / \mathrm{CAM} / \mathrm{CAE}$. Maka dapat disimpulkan bahwa tujuan kegiatan ini dapat tercapai.

Ketercapaian target materi pada kegiatan pelatihan dalam Pengabdian Kepada Masyarakat ini cukup baik, karena materi pelatihan telah dapat disampaikan secara keseluruhan. Materi pelatihan yang telah disampaikan adalah:

- Pengenalan dasar-dasar tentang CAD/ CAM/CAE yang meliputi kelebihan dan aplikasinya di industri

- Pengenalan menu-menu pada AutoCAD untuk pembuatan gambar Dua Dimensi (2D) dan tiga dimensi (3D).

- Proses menggambar komponen mesin baik Dua Dimensi (2D) maupun tiga dimensi (3D).

- Proses assembly komponen dan rendering sehingga mesin yang kita gambar akan nampak seperti mesin sebenarnya.

- Evaluasi hasil penguasaan $\mathrm{CAD} /$ CAM/CAE dan Software AutoCAD 2D $\& 3 \mathrm{D}$

Kemampuan peserta dilihat dari penguasaan materi masih kurang dikarenakan waktu yang singkat dalam penyampaian materi dan kemampuan para peserta yang berbedabeda, Hal ini disebabkan jumlah materi yang banyak hanya disampaikan dalam waktu sehari sehingga tidak cukup waktu bagi para peserta untuk memahami dan mempraktekkan secara lengkap semua materi yang diberikan.

Secara keseluruhan kegiatan pelatihan Dasar-Dasar CAD/CAM/CAE dan Software AutoCad ini dapat dikatakan berhasil. Manfaat yang diperoleh guru adalah dapat mengenal CAD/CAM/CAE dan aplikasinya serta dalam menggunakan software AutoCAD, sehingga akan membantu dalam proses pembelajaran nantinya.

\section{KESIMPULAN}

Berdasarkan kegiatan yang telah dilakukan dan pembahasan yang telah dijelaskan didepan, bisa diambil beberapa

1. Program pelatihan dapat diselenggarakan dengan baik dan berjalan dengan lancar sesuai dengan rencana kegiatan yang telah disusun.

2. Kegiatan ini mendapat sambutan sangat baik terbukti dengan keaktifan peserta mengikuti pelatihan dengan tidak meninggalkan tempat sebelum waktu pelatihan berakhir.

3. Terjadinya peningkatan pengetahuan tentang konsep perancangan produk melalui pengenalan dasar-dasar $\mathrm{CAD} /$ $\mathrm{CAM} / \mathrm{CAE}$ dan peningkatan kemampuan dan motivasi dalam mendalami desain dengan software CAD, khususnya AutoCAD

4. Kegiatan ini sangat bermanfaat bagi guruguru SMK bidang keahlian teknik mesin di wilayah kabupaten Bekasi, Jawa Barat

Berdasarkan evaluasi yang telah dilakukan dapat diajukan beberapa saran sebagai berikut:

1. Kegiatan pelatihan ini perlu diselenggarakan secara berkelanjutan agar kemampuan dan ketrampilan guru dibidang perancangan khususnya $\mathrm{CAD} / \mathrm{CAM} / \mathrm{CAE}$ selalu meningkat dan ketrampilan dalam menggunakan 
software AutoCAD atau software sejenis menjadi lebih baik.

2. Waktu pelaksanaan kegiatan pelatihan perlu ditambah agar tujuan kegiatan dapat tercapai sepenuhnya.

3. Setelah mengikuti pelatihan ini, diharapkan para guru peserta pelatihan dapat lebih mengembangkan dan melatih kemampuannya secara mandiri, agar kemampuannya selalu meningkat. Dan diharapkan guru mampu memberikan pelatihan serupa ke sesama guru yang belum mendapatkan pelatihan dan kepada siswa-siswa SMK tempat guru mengajar, agar membekali siswa dalam memasuki dunia kerja.

\section{DAFTAR PUSTAKA}

[1] Achmad Kholil, MODUL AUTOCAD 2D \& 3D, Universitas Negeri Jakarta, 2009
[2] Sugeng Kurniawan, Presentation of General Lecture in UNJ "C4 in the Working Job", Research \& Develompment, LG Electronics Indonesia, 2013

[3] Kunwoo Lee, Principles of CAD/ CAM/CAE, 2012

[4] AutoDesk, Tutorial AutoCAD 2010, 2010

[5] Suparno Sastra M, Professional 3d Modeling With Autocad $+\boldsymbol{C d}$, ELEX MEDIA,2013

[6] M Sholeh, Belajar Otodidak Autocad 2d \& 3d, Informatika, 2011

[7] Teknik dan Latihan Modeling 3 Dimensi Kristen Kurland, 3D Tutorial AutoCAD 2007, 2007.

[8] Panduan Berlatih : Modul Pelatihan AutoCAD 2006, www.igun. web.id 